\title{
Notas
}

\section{EL CINCUENTENARIO DE LA COMISIÓN TEOLÓGICA INTERNACIONAL. APORTES A LA TEOLOGÍA FUNDAMENTAL, LA CRISTOLOGÍA Y LA ECLESIOLOGÍA}

RESUMEN: En la teología cosechamos con gratitud lo que otros sembraron entre lágrimas y sembramos con generosidad lo que otros cosecharán. En 2019 se cumplieron cincuenta años de la Comisión Teológica Internacional (CTI) creada por san Pablo VI a pedido de la primera asamblea del Sínodo de los Obispos para proseguir la colaboración vivida durante el Concilio Vaticano II. La CTI testimonia una comunión diacrónica y sincrónica con corsi e recorsi. Este artículo destaca algunos aportes a la teología sistemática dados en sus 30 documentos. Hace una mirada de conjunto al estilo de la Comisión y al método de trabajo; señala los grandes aportes en la teología fundamental y a los misterios centrales de la fe en diálogo con tendencias actuales; dibuja la figura sinodal del teólogo.

PALABRAS CLAVE: Comisión Teológica Internacional; cincuentenario; comunidad teológica; método sinodal; teología fundamental; teología de los misterios de Dios, Cristo y la Iglesia.

Universidad Católica Argentina, Facultad de Teología: galli@uca.edu.ar;

ORCID: https://orcid.org/0000-0002-6717-537X 


\section{In the Fiftieth Anniversary of the International Theological Commission. Contributions to Fundamental Theology, Christology and Ecclesiology}

ABSTRACT: In theology we gratefully reap what others sowed through tears and generously sow what others will reap. 2019 marked the $50^{\text {th }}$ anniversary of the International Theological Commission (ITC) created by Saint Paul VI at the request of the first assembly of the Synod of Bishops to continue the collaboration lived during the Second Vatican Council. The CTI testifies to a diachronic and synchronic communion with corsi e recorsi. Some contributions to systematic theology given in its 30 documents are highlighted. It takes a general look at the style of the Commission and the method of work; points out the great contributions to fundamental theology and to the central mysteries of the faith in dialogue with current trends; draw the synodal figure of the theologian.

KEY WORDS: International Theological Commission; fiftieth anniversary; theological community; synodal method; fundamental theology; theology of the mysteries of God, Christ and the Church.

A Gérard Philips $† 1972$

A Philippe Delhaye $† 1990$

Desde Juan XXIII: Gaudet Mater Ecclesia, el Concilio Vaticano II: Gaudium et spes, y Pablo VI: Gaudete in Domino, hasta Francisco: Evangelii gaudium (EG), la Iglesia proclama con renovado gozo la Buena Notica. La alegría nos mueve a comunicar a las nuevas generaciones lo que recibimos de quienes nos precedieron en la fe. También nos anima a evangelizar cosechando con gratitud lo que otros sembraron entre lágrimas y sembrar con generosidad lo que otros cosecharán entre cantos: «Así, el que siembra y el que cosecha comparten una misma alegría» (Jn 4,36). En estos cincuenta años cosechamos y damos gracias a Dios por lo que tantos sembraron en la Comisión Teológica Internacional (CTI).

La CTI fue fundada por san Pablo VI a propuesta de la primera asamblea del Sínodo de los Obispos para proseguir la colaboración entre la teología y el magisterio vivida en el Concilio Vaticano II. Existe un relato de su historia de 1969 a 1990 hecho por don Emanuele Avallone. Su tesis analiza muchos documentos y estudia los años en los que fueron secretarios dos grandes teólogos belgas: Gérard Philips de 1969 a 1972 y Phillipe Delhaye de 1972 a 1989. Dedico esta contribución a la memoria de ambos.

El hecho de participar en la CTI ayuda a hacer teología reflexionando, investigando, conversando, discutiendo, redactando y aprobando textos para comunicar un pensamiento común. Ejercitar la teología de forma 
colegial a nivel mundial exige una actitud de colaboración permanente. La CTI es testimonio de una comunión diacrónica y sincrónica con variados acentos y momentos. Está pendiente la tarea de completar la historia hasta el presente y analizar los frutos y contingencias de los quinquenios.

Aquí me concentraré en mostrar algunos aportes de sus documentos a la teología sistemática en cuatro pasos: 1) una mirada de conjunto al estilo y los documentos; 2) aportes en la teología fundamental; 3) contribuciones a los misterios centrales de la fe en la teología dogmática; 4) la figura sinodal del teólogo.

\section{ESTILO, MÉTODOS, DOCUMENTOS}

La Comisión se sitúa en una trama de sujetos institucionales que investigan y enseñan la fe de la Iglesia católica. En el magisterio del Obispo de Roma y de sus auxiliares se distinguen los textos directos de la enseñanza pontificia, otros que emanan de la Congregación para la Doctrina de la $\mathrm{Fe}(\mathrm{CDF})^{1}$, los que proceden de otros dicasterios, y los emanados de organismos de estudio, como la nueva Pontificia Comisión Bíblica (PCB, 1971) y la Comisión Teológica Internacional ${ }^{2}$, situadas en la mencionada Congregación y presididas por su prefecto, hoy cardenal Luis Ladaria, SJ.

Los distintos sujetos han tratado temas similares. Por ejemplo, la acción del Espíritu Santo en la Iglesia y en los pueblos está analizada por la encíclica Redemptoris missio de Juan Pablo II (1991), la declaración Dominus Iesus de la CDF (2000) y el documento El cristianismo y las religiones de la CTI (1997). Hay consideraciones sobre la labor teológica en muchos textos pontificios, como el Proemiun a la Constitución Veritatis gaudium del papa Francisco (2017), en la CDF, que publicó Donum veritatis sobre la vocación eclesial del teólogo (1990), o La Teología hoy (2012) de la CTI. Como se percibe, hay una rica pluralidad de desarrollos en la unidad de la fe católica.

Los presidentes de la CTI han sido F. Seper (1969-1981); J. Ratzinger (1981-2005), W. Levada (2005-2012), L. Müller (2012-2017), L.

${ }^{1}$ Cf. Congregación para la Doctrina de la Fe. Documentos 1966-2007. Madrid: BAC, 2007; Id. Documentos 2008-2011. Madrid: BAC, 2012.

2 Cf. Comisión Teológica Internacional. Documentos 1969-2014. Madrid: BAC, 2017. Commission Théologique Internationale. Textes et Documents I (1969-1985). Paris: Cerf, 1988; Id. Documents II (1986-2009). Paris, Cerf, 2013. Commissione Teologica Internazionale. Documenti 1969-2004. Bologna: EDS, 2006 (2010). 
Ladaria (2017-). Después de Delhaye, los secretarios han sido G. Cottier (1989-2004); L. Ladaria (2004-2009), Ch. Morerod (2009-2011), S.-T. Bonino (2012-). El grupo del primer quinquenio estuvo formado por destacados teólogos, varios peritos conciliares ${ }^{3}$. En sus nueve quinquenios participamos 172 teólogos y teólogas de varias generaciones, tendencias y culturas. El ejemplo del último quinquenio es significativo: de los 30, 14 eran de Europa, 8 de América (5 de América Latina), 4 de Asia, 3 de África, 1 de Oceanía. En un momento del periodo, las tres subcomisiones quedaron coordinadas por tres teólogos de lengua española.

La CTI produjo 30 documentos $^{4}$, frutos de un largo proceso de elaboración colectiva, como dice el Documento 13 (1985, Intr.) $)^{5}$. Magisterio y

${ }^{3}$ Los 30 miembros nombrados por Pablo VI para el quinquenio 1969-1974 fueron: P. B. Ahern, C.P. - Rev. H. U. von Balthasar - P. L. Bouyer, dO - P. W. Burghardt, S.I. - S.E. Mons. C. Colombo - P. Y. Congar, O.P. - Mons. P. Delhaye - Rev. J. Feiner - P. A. Feuillet, P.S.S. - Rev. L. Gera - Rev. O. González de Cardedal - P. I. Khalifé, S.I.- P. F. Lakner, S.I.- P. M-. Le Guillou, O.P. - P. J. Lescrauwaet, M.S.C. - P. Bernard Lonergan, S.I.- P. Henri de Lubac, S.I. - P. Andreas H. Maltha, O.P. - Mons. Jorge Medina Estévez - P. Peter Nemeshegyi, S.I. - Mons. St. Olejnik - Mons. G. Philips (secretario) - P. K. Rahner, S.I. - Rev. J. Ratzinger - Mons. R. Mascarenhas Roxo - P.T. Sagi-Bunic, O.F.M.Cap.- Mons. R. Schnakenburg - Rev. H. Schürmann - S.E. Mons. T. Tshimbangu - P. C. Vagaggini, O.S.B.

${ }^{4}$ El elenco de los 30 documentos: 1. Reflexiones sobre los fines y los métodos de la Comisión (1969); 2. El sacerdocio católico (1970); 3. La unidad de la fe y el pluralismo teológico (1972); 4. La apostolicidad de la Iglesia y la sucesión apostólica (1973); 5. La moral cristiana y sus normas (1974): tesis de Schürmann y von Balthasar; 6. Magisterio y teología (1975); 7. Promoción humana y salvación cristiana (1976); 8. La doctrina católica sobre el sacramento del matrimonio (1977): proposiciones de la CTI; 16 tesis mariológicas de Martelet; 9. Algunas cuestiones referentes la cristología (1979); 10. Teología, cristología, antropología (1981); 11. La reconciliación y la penitencia (1982); 12. Dignidad y derechos de la persona humana (1983); 13. Temas selectos de eclesiología (1985); 14. La conciencia que Jesús tenía de sí mismo y de su misión (1985); 15. La fe y la inculturación (1988); 16. La interpretación de los dogmas (1989); 17. Algunas cuestiones actuales de escatología (1992); 18. Algunas cuestiones sobre la teología de la Redención (1995); 19. El cristianismo y las religiones (1997); 20. Memoria y reconciliación: La Iglesia y las culpas del pasado (2000); 21. El diaconado: evolución y perspectivas (2002); 22. Comunión y servicio: La persona humana creada a imagen de Dios (2004); 23. La esperanza de salvación para los niños que mueren sin bautismo (2007); 24. En busca de una ética universal: nueva mirada sobre la ley natural (2009); 25. Teología hoy: Perspectivas, principios y criterios (2012); 26. Dios Trinidad, unidad de los hombres. El monoteísmo cristiano contra la violencia (2014); 27. El sensus fidei en la vida de la Iglesia (2014); 28. La sinodalidad en la vida y en la misión de la Iglesia (2018); 29. La libertad religiosa para el bien de todos (2019); 30. La reciprocidad entre fe y sacramentos en la economía sacramental (2020; este documento fue aprobado en la sesión plenaria de 2019).

${ }^{5}$ Las citas de los documentos de la CTI se hacen en el interior del texto con el año y el párrafo correspondiente, y sin la sigla cf. 
Teología decía: «Es común — aunque de forma diversa — la manera a la vez colegial y personal con la cual es ejercitada la función del Magisterio y de los teólogos» (1975, tesis 4). La Teología hoy habla, por primera vez, de la comunidad de los teólogos (2012, 45-50).

La producción fue constante, si bien estuvo marcada por circunstancias internas y externas. En el último periodo logramos investigar, completar y editar los tres temas. La CTI aprovechó la experiencia conciliar y el método de trabajo que Mons. Philips le transmitió: delimitar temas, trabajar por subcomisiones, emplear métodos rigurosos, debatir con argumentos, mediar las posiciones y elaborar textos que, por el intercambio entre el grupo y el plenario, ganen consenso y sean perfeccionados en contenido y estilo ${ }^{6}$.

Los miembros trabajan con un profundo sensus Ecclesiae y un serio estilo sinodal, con el deseo de forjar «un órgano para la formación del consenso ${ }^{7}$. En los inicios, marcados por la incertidumbre y las tensiones, fueron decisivas las figuras mediadoras del presidente Seper y el secretario Philips, un verdadero homo conciliaris ${ }^{8}$. Luego, durante veinte años y en situaciones críticas, Delhaye mantuvo la continuidad de un colectivo formado por teólogos profesionales con personalidades fuertes y posiciones firmes. Primó la colaboración amigable y la búsqueda de fuentes comunes, horizontes hermenéuticos y mediaciones lingüísticas. Una investigación en diálogo como la de la CTI requiere ser animada por un ethos integrador ${ }^{9}$. Las instituciones teológicas deberían promover más las investigaciones que generan textos colectivos creativos y consensos teológicos parciales.

La Comisión no trata problemas particulares, como el examen de un libro, sino que estudia problemas doctrinales fundamentales que resultan cruciales para la vida de la Iglesia. Por eso algunos títulos comienzan así: «Algunas cuestiones...» $\mathrm{O}$ "Cuestiones selectas...», indicando la selección de los temas y lo inacabado de la reflexión. Cada documento ofrece una

${ }^{6}$ Cf. Gérard Philips. "Méthodes théologiques de Vatican II". En Théologie. Le service théologique dans l'Église. Mélanges offers au Pére Congar, 11-35. Paris: Cerf, 1974.

7 Enmanuele Avallone. La Comissione Teologica Internationale. Storia e prospettive. Venezia: Marcianum Press, 2016, 71.

8 Albert Descamps. "In memoriam Monseigneur G. Philips". Revue Theólogique de Louvain 3 (1972): 378-381, 380.

9 Cf. Carlos María Galli. "Pensar conjuntamente en teología y en filosofía. Un estilo dialogal, itinerante, integrador". Teología 129 (2019): 9-65. 
valiosa síntesis abierta. Muchos textos son valiosísimos y juntos podrían constituir la base amplia de una formación teológica de posgrado.

Los documentos, con sus valores y límites, asumieron los debates de cada momento. Los clasifico en tres grupos: 1) Teología fundamental, revelación, fe, dogmas, magisterio, hermenéutica, teología. 2) Teología dogmática, Dios, Cristo, salvación, Iglesia / María, evangelización, inculturación. 3) Antropología, escatología, teología moral, teología sacramental: bautismo, reconciliación, matrimonio; ministerios ordenados: sacerdocio y diaconado. En este estudio me limito a los documentos sobre la teología fundamental y sobre los misterios interrelacionados de Dios, Cristo, la Iglesia y el hombre.

\section{LA TEOLOGÍA FUNDAMENTAL}

Presento aportes siguiendo este orden: contexto, documentos, núcleos centrales, transversalidades. El contexto general viene dado por la notable renovación de la teología fundamental a partir de la Constitución Dei Verbum. En el postconcilio se comenzó a superar la antigua apologética y a desarrollar muchas cuestiones relativas a la Revelación de Dios, su trasmisión en la Iglesia, la respuesta de la fe, la naturaleza y el método de la teología, el servicio del magisterio, las relaciones con las iglesias, las religiones y la filosofía. La teología fundamental sigue distintas formas de diálogo entre la fe, la religión y la razón.

Los documentos pertinentes se refieren a la figura de la Comisión (1), la fe y la teología (3), el magisterio y la teología (6), la interpretación de los dogmas (16), la teología hoy (25), el sensus fidei (27). Corresponde situar aquí el texto sobre la reciprocidad entre fe y sacramentos en la economía sacramental (30) porque expone la índole sacramental de la fe cristiana. Los seis primeros documentos nacieron por situaciones contingentes, pero tratan temas con valor permanente. Aquí señalo tres aportes puntuales.

El primer punto clave es la hermenéutica de la Palabra de Dios, la articulación de los lugares teológicos y el desarrollo de los dogmas. El documento La interpretación de los dogmas dice que, en el dogma de la Iglesia, lo que se juega es la interpretación correcta de la Sagrada Escritura. En esa tarea «el Magisterio no juzga la Palabra de Dios sino la precisión de la interpretación» (1989, C, I, 3). 
El segundo es el proceso que va de la fe común a la pluralidad de expresiones teológicas, analizado en el documento La unidad de la fe y el pluralismo teológico. Entonces se debatía con vehemencia la cuestión del pluralismo. La primera afirmación expresa la riqueza insondable del misterio de Cristo:

«La unidad y la pluralidad en la expresión de la fe tienen su fundamento último en el misterio mismo de Cristo, el cual, aunque es misterio de recapitulación y reconciliación universales (cf. Ef 2, 11-22), excede las posibilidades de expresión de cualquier época de la historia y se sustrae por eso a toda sistematización exhaustiva (cf. Ef 3, 8-10)» (1972, 1).

Un tercer punto son los vínculos entre el magisterio y la teología al servicio de la fe. Magisterio y teología afirma el carácter análogo de ambas formas de enseñanza (1975, tesis I) a partir de elementos comunes (tesis II-IV) y diferencias (tesis V-IX) para promover relaciones fecundas (tesis X-XI). La autoridad del magisterio brota de su naturaleza apostólica y sacramental (tesis VI/1); la autoridad de la teología surge de su cualificación científica, que en la ciencia de la fe está unida a la experiencia vivida (tesis $\mathrm{VI} / 2$ ).

Ahora señalo cuatro temas transversales que tienen proyecciones creativas en la teología dogmática.

1. Se presenta al Pueblo de Dios como sujeto - comunitario, histórico, sinodal — de la fe cristiana. Cuatro textos analizan la cuestión. El dedicado a la unidad y el pluralismo recuerda que la verdad de la fe está vinculada a su desarrollo histórico. «En consecuencia, la ortodoxia no consiste en el consenso a un sistema, sino en la participación al progreso de la fe y así al Yo de la Iglesia que permanece una a través del tiempo y que es el verdadero sujeto del Credo» (1972, tesis 4). La Iglesia es el sujeto englobante de la fe en el cual se unen las teologías neotestamentarias y los dogmas a través de la historia (tesis 6).

El fundamento de la continuidad de la Paradosis viva está en que la Iglesia es el sujeto de la fe que trasciende el espacio y el tiempo (1989, B, III, 1). En el Jubileo, al fundamentar la purificación de la memoria y la confesión de las culpas, la comisión publicó su documento Memoria y reconciliación: La Iglesia y las culpas del pasado. Apoyada en la enseñanza conciliar sobre la dimensión histórico-escatológica de la Iglesia y de su catolicidad incluyente de espacios y tiempos, declara que el Pueblo de Dios es «un sujeto absolutamente único en la historia humana, a tal punto 
que puede hacerse cargo de los dones, los méritos y las culpas de sus hijos de hoy, como también de aquellos de ayer» (2000, III, 1).

Para el documento 28 «la sinodalidad expresa que el ser sujeto de toda

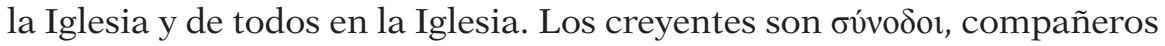
de camino, llamados a ser sujetos activos en cuanto partícipes del único sacerdocio de Cristo» $(2018,55)$. Este texto manifiesta que el Pueblo de Dios en camino «constituye un singular sujeto histórico en el que ya está presente y operante el destino escatológico de la unión definitiva con Dios y de la unidad de la familia humana en Cristo» $(2018,51)$.

2. En línea con lo anterior se presenta la doctrina del sensus fidei fidelium. El Símbolo de la Fe puede ser rezado en primera persona singular o plural. Decir yo creo es decir que adhiero a lo que nosotros creemos. El acto personal del creyente que hace teología reposa sobre la fe de la Iglesia, expresada en el sentido de la fe de todos los creyentes. Este tema ya aparece en 1975 como un factor vinculante tanto para el magisterio como para la teología. Ese documento recuerda: «la Palabra de Dios está presente en toda época en el sentido común de la fe de todo el Pueblo de Dios» (1975, tesis III). La misma idea reaparece en el documento sobre La interpretación de los dogmas en 1989 (1989, C, II, 1).

El documento El 'sensus fidei' en la vida de la Iglesia reconoce que el Pueblo de Dios es el sujeto del sensus fidei y distingue dos aspectos conexos: el sensus fidei fidelis o instinto personal del creyente en comunión y el sensus fidei fidelium o forma eclesial del sentido de la fe. Su expresión más plena es el consensus fidei o sensus Ecclesiae que atestigua que una doctrina pertenece a la fe apostólica. Ya La Teología hoy afirmaba que el sensus fidelium es fundamento y locus del trabajo teológico.

«El sensus fidelium es de gran importancia para los teólogos. No es sólo objeto de atención y respeto, sino también fundamento y locus para su tarea. Por una parte, los teólogos dependen del sensus fidelium, puesto que la fe que ellos exploran y explican vive en el Pueblo de Dios. Los teólogos mismos deben participar en la vida de la Iglesia para tener un conocimiento real de ella. Por otra parte, el servicio particular de los teólogos en el interior del Cuerpo de Cristo es precisamente el de explicar la fe de la Iglesia tal como se contiene en las Escrituras, la liturgia, los credos, los dogmas, los catecismos y en el mismo sensus fidelium. Los teólogos contribuyen a esclarecer y articular el contenido del sensus fidelium [...]» $(2012,35)$. 
Benedicto XVI siempre habló de la fe de los pequeños. En una catequesis recordó que Juan Duns Scoto, al explicar la doctrina de la Inmaculada Concepción, llamó la atención sobre lo que espontáneamente creía el pueblo cristiano acerca de la Virgen y lo manifestaba en expresiones de la piedad y el arte.

«El Pueblo de Dios precede a los teólogos y todo esto gracias a ese sobrenatural sensus fidei, es decir, a la capacidad infusa del Espíritu Santo, que habilita para abrazar la realidad de la fe con la humildad del corazón y de la mente. En este sentido, el Pueblo de Dios es "magisterio que precede", y que después la teología debe profundizar y acoger intelectualmente. ¡Ojalá los teólogos escuchen siempre esta fuente de la fe y conserven la humildad y la sencillez de los pequeños! ${ }^{10}$.

Para Francisco la piedad católica popular es un lugar teológico para saborear y pensar la fe. "Las expresiones de la piedad popular tienen mucho que enseñarnos y, para quien sabe leerlas, son un lugar teológico al que debemos prestar atención, particularmente al pensar la nueva evangelización» (EG 126).

3. Una tercera transversalidad está dada por la verdad en la historia, tema desarrollado en diálogo con la filosofía desde las fuentes clásicas (documentos 24, 29), la hermenéutica metafísica (documento 16) y la hermenéutica histórica (documento 20). La tesis V de 1972 mostró que la verdad de la fe, por la Encarnación, se vive en un caminar histórico y práctico. La interpretación de los dogmas afirma: «La Iglesia, en su anuncio del único Evangelio, revelado en el tiempo y, sin embargo, válido para todos los pueblos y todos los tiempos, puede ir al encuentro de la inteligencia, que es histórica y, a la vez abierta a lo universal; puede purificarla y conducirla a su más profundo cumplimiento» (1989, II, A, 1, 4).

4. Lex orandi, lex credendi. La CTI expone varios temas empleando el doble principio del auditus fidei y el intellectus fidei que configuran el método de la scientia fidei. Con el primero escucha la Palabra de Dios en la comunión del Pueblo de Dios y asume los contenidos de la Revelación como son explicitados en la Sagrada Escritura, la tradición apostólica, el sensus fidelium, la teología de los santos y los doctores, el magisterio, considerando las voces de la comunidad teológica y los signos de los

${ }^{10}$ Cf. Benedicto XVI. "Catequesis sobre Juan Duns Scoto en la audiencia general del 7/7/2010". En Los Maestros III. Franciscanos y dominicos. Catequesis de los miércoles. Buenos Aires: Agape, 2010, 99-107. 
tiempos. Esta forma de proceder se verifica en todos sus documentos; muchos de ellos tienen una impresionante riqueza bíblica e histórica. Así, la mayoría sigue el estilo de teologizar del Vaticano II.

Con el ejercicio constructivo y creativo del intellectus fidei, la CTI piensa los misterios de la fe, sintetiza el desarrollo histórico-dogmático, fundamenta y sistematiza las doctrinas, y realiza una reflexión especulativa que comunica sus riquezas intrínsecas y las perspectivas actuales. Ofrece una ratio fide illustrata, una construcción de la razón teológica, una progresión circular entre teología y filosofía.

La CTI utiliza el criterio litúrgico y hermenéutico sintetizado en el lema lex credendi, lex orandi. Así muestra la conexión entre la tradición apostólica y la comunión eclesial actual (1989, C, II, 2) y defiende la escatología intermedia con la súplica por los difuntos (1990, B, 11). El documento sobre la esperanza de la salvación para los niños que mueren sin haber recibido el bautismo culmina en la sección Spes orans. Razones de la esperanza. La misericordia de Dios, la solidaridad en Cristo y la comunión de los santos sostienen la esperanza de la salvación universal. A eso colabora el hecho de que, después del Concilio, la Iglesia latina estableció un rito especial de exequias para niños no bautizados (2007, III, 5).

\section{LA TEOLOGÍA DOGMÁTICA}

La teología dogmática articula el sentido universal del misterio de Dios y de la economía salvífica realizada por Cristo y comunicada en el Espíritu mediante una reflexión narrativa y argumentativa que se traduce en expresiones formuladas de un modo sistemático y crítico, comunicables universalmente. Después de la encíclica Aeterni Patris de León XIII (1878) se ha dado una renovación de la teología católica tanto positiva como especulativa mediante la vuelta a las fuentes y la puesta al día, que la puso en una situación comparable a la gran patrística de los siglos IV-V y la alta escolástica del siglo XIII ${ }^{11}$.

La reflexión teológica tiene por objeto los misterios de la fe. Los misterios son personas, acontecimientos o comunión de personas: las Tres personas en la identidad del único Dios; la persona de Jesucristo, Dios-Hombre; la

${ }^{11}$ Ghislain Lafont. Histoire théologique de l'Église catholique. Itinéraire et formes de la théologie. Paris: Cerf, 1994, 11, 37. 
Iglesia como comunión de personas en el Espíritu; María, la Madre de Dios; los santos del cielo, los peregrinos en la tierra; los misterios sacramentales; la familia humana en la casa común. La teología desea entender y expresar los nexos de los misterios entre sí (nexus mysteriorum inter se). Por eso aquí empleo el esquema usado para la teología fundamental — contextos, documentos, puntos centrales, transversalidades- a la reflexión sobre los misterios de Dios, Cristo, la Iglesia y el ser humano.

\subsection{Dios en CRisto y CRisto en Dios}

El primer contexto viene dado por el notable desarrollo de la doctrina trinitaria de Dios en las últimas décadas. Varios factores han causado este progreso: la explicitación de la enseñanza conciliar sobre el fundamento trinitario de la Iglesia (LG 2-4) y su misión (AG 2-4); la novedad de la cristología trinitaria a partir del misterio pascual desde la Theologie der Drei Tage de Hans Urs von Balthasar (1969); los debates acerca de la unidad y la distinción entre la teología filosófica y la teología revelada trinitaria; el mejor conocimiento de las fuentes y doctrinas de doctores trinitarios de la patrística y el medioevo; el resurgimiento de la pneumatología con la celebración de los 1600 años del Concilio de Constantinopla I (1981); el impulso dado a la teología trinitaria por tres encíclicas de san Juan Pablo II y por la estructura trinitaria del Jubileo de 2000; la reflexión sistemática acerca del misterio de Dios-Comunión como horizonte primero y último de una teología y de una ontología personalista y comunional.

El segundo contexto es el peculiar florecimiento de la cristología. Desde el Vaticano II se ha desarrollado una impresionante reflexión cristológica poliédrica, que no tiene equivalentes con lo sucedido en otras épocas. Esto se verifica en los numerosos estudios de las fuentes porque se multiplicaron los trabajos de la cristología bíblica, dogmática, patrística, medieval, litúrgica, fundamental, dogmática, e incluso filosófica ${ }^{12}$. Por otra parte, se desplegaron muchos enfoques acerca de Jesucristo que generaron cristologías con diversos adjetivos: trascendental, existencial, histórica,

12 Xavier Tilliette. Le Christ de la Philosophie. Paris: Cerf, 1990; Id. La Settimana Santa dei filosofi. Brescia: Morcelliana, 1992. 
cósmica, teologal, trinitaria, pneumatológica, soteriológica, liberadora, kerigmática, pastoral, inculturada, sacramental, eucarística, espiritual...

Los documentos acerca de Dios en Cristo y Cristo en Dios son: Cuestiones referentes a la cristología (1979); Teología, cristología, antropología (1981); La conciencia que Jesús tenía de sí mismo y de su misión (1985); Cuestiones sobre la teología de la Redención (1995); Dios Trinidad, unidad de los hombres. (2014). Los textos referidos a Dios - Cristo salvador y a la salvación son: Promoción humana y salvación cristiana (1976); Cuestiones actuales de escatología (1992); El cristianismo y las religiones (1997); La esperanza de salvación para los niños que mueren sin bautismo (2007).

Algunas cuestiones de cristología y Teología, cristología, antropología forman un todo. Su alto nivel muestra que, en el segundo quinquenio, la CTI tuvo grandes exponentes de la teología sistemática, como Alfaro, von Balthasar, Cantalamessa, Congar, González de Cardedal, Le Guillou, Lehmann, Martelet, Medina, Ratzinger, Semmelroth, Tillard. Desde 1970 se publicaron trabajos sobre Jesús en el Nuevo Testamento. Algunos fueron escritos por exégetas que integraron la CTI: Schnackenburg, Schürmann, Gnilka, Söding. Varios teólogos desarrollaron cristologías trinitarias y pneumatológicas, y teologías trinitarias y antropologías teológicas con una fuerte impronta cristológica. Entre los miembros de la CTI nombro a: Alfaro, Bouyer, Coda, Congar, De Franca Miranda, Ferrara, Forte, Gesché, González de Cardedal, Kasper, Ladaria, Le Guillou, Martelet, Ratzinger, von Schönborn...

En la abundante literatura cristológica de esa etapa hubo lecturas reduccionistas, pero hubo muchas más síntesis integradoras. Grandes teólogos procuraron articular perspectivas en una cristología integral. De una forma sistemática, en la senda de la espiritualidad ignaciana y en diálogo con la tridimensionalidad hegeliana, Emilio Brito integró cuestiones expresadas en los binomios: Jesús de la historia y Cristo de la fe; cristología y soteriología; cristología descendente y ascendente; teología y antropología ${ }^{13}$.

${ }^{13}$ Cf. Emilio Brito. "Gloria Unigeniti. Pour une christologie post-hégélienne". En La christologie de Hegel. Verbum crucis, 535-656. Paris: Beauchesne, 1983, que integra en cuatro dimensiones una pluralidad de perspectivas. Cito trabajos de algunos miembros de la CTI sobre estas cuestiones y en aquellos años: Luis Ladaria. "Cristología del Logos y cristología del Espíritu”. Gregorianum 61 (1980): 353-360. Yves Congar. "Pour une christologie pneumatologique". En Je crois en l'Esprit Saint III, 
El texto Algunas cuestiones de cristología puso buenas bases para integrar de forma equilibrada los aportes del conocimiento histórico de Jesús y las afirmaciones dogmáticas que representan la fe de la Iglesia. Después, en 1984, en una forma distinta pero complementaria, la Pontificia Comisión Bíblica publicó su valioso volumen Biblia y Cristología (1985). El texto Algunas cuestiones sobre la teología de la Redención expresa la unidad entre el Salvador y su obra redentora superando cualquier cesura entre cristología y soteriología. Bernard Sesboüé ya había dado ese paso integrando las líneas descendentes y ascendentes de la soteriología y dando una síntesis original sobre la reconciliación ${ }^{14}$.

Teología, cristología, antropología es uno de los mejores documentos especulativos. La cuestión fundamental es la relación del misterio de Cristo - vere Deus, vere homo- con la revelación del misterio del Dios único como Trinidad y del misterio del ser humano como imago Trinitatis y filio in Filio. Empleando de forma análoga el principio calcedoniano, el texto afirma la unidad en la distinción entre cristocentrismo y teocentrismo porque la economía de Jesucristo revela al único Dios que es Trinidad de personas. Expresa el vínculo entre la preexistencia y la proexistencia de Jesús, desarrollado por Schürmann y von Balthasar. Ese binomio manifiesta que la eterna relación del Hijo con el Padre en el Espíritu es la fuente y el fundamento de su vida y de su muerte pascual pro nobis, pro multis $(1979,9)$.

El misterio del hombre sólo se esclarece plenamente a la luz del misterio del Verbo encarnado. Como dice el mismo documento conciliar: «Cristo, el nuevo Adán, en la misma revelación del misterio del Padre y de su amor, revela plenamente el hombre al propio hombre y le manifiesta su vocación sublime» (GS 22) ${ }^{15}$. Esta frase explica la unidad cristocéntrica entre el teocentrismo y el antropocentrismo, que es una clave de la teología de Juan Pablo II (Dives in Misericordia 1) y de la CTI (1981, I, C-E).

219-228. Paris: Cerf, 1983. Walter Kasper. Teología e Iglesia. Barcelona: Herder, 1989, 266-321. Olegario González de Cardedal. Cuatro poetas desde la otra ladera. Unamuno, Jean Paul, Machado, Oscar Wilde. Prolegómenos para una cristología. Madrid: Trotta, 1996, 537-630.

${ }_{14}$ Cf. Bernard Sesboüé. Jesucristo, el único Mediador. Vol. 1. Salamanca: Secretariado Trinitario, 1990, 41-124.

15 Cf. Luis Ladaria. "El hombre a la luz de Cristo en el Concilio Vaticano II". En Vaticano II. Balance y perspectivas, editado por René Latourelle, 705-714. Salamanca: Sígueme, 1989. 


\subsection{Amor DE Dios y DignidAD DEL HOMBRE}

Un eje transversal es lo que llamo el único centro bipolar de la fe cristiana. El texto sobre Dios redentor afirma que la cristología y la Trinidad son las dos doctrinas-clave del cristianismo.

«Este mensaje de esperanza se apoya en las dos doctrinas-clave cristianas de la Cristología y la Trinidad. En esas doctrinas se encuentra la razón última para la comprensión cristiana de la historia humana y la persona humana, hecha a la imagen del Dios Trino, una Unidad en Comunión, redimida por amor por el Hijo único de Dios, Jesucristo, con el fin de dar participación en la vida divina, para la cual, en primer lugar, fuimos creados. Esa participación está indicada por la doctrina de la resurrección del cuerpo, cuando los seres humanos, en su realidad total, compartan la plenitud de la vida divina» (1995, I, c).

La concentración cristológica y el desbordamiento trinitario expresan una teología situada en el Centro del Centro: Jesucristo, centrado en el Padre y centrador por el Espíritu. El texto sobre Dios-Trinidad, unidad de los hombres tiene pasajes de una honda densidad trinitaria y explora las relaciones entre la confesión trinitaria del Dios único, la verdad sobre Cristo y un humanismo universal (2014, Intr.).

El misterio de Dios-Amor funda una analogía caritatis que articula el amor de Dios con el amor al prójimo $(1981,10)$. Me gusta resumir el corazón de la fe y de la teología en dos textos del Nuevo Testamento. El primero, de san Juan, anuncia: Dios es Amor (1Jn 4,8.16). El segundo, de san Pablo, enseña: lo más importante es el amor (1Co 13,13). Francisco predica la misericordia de Dios-Amor. El mensaje de Cristo se expresa en el kerigma fundante del amor trinitario, pascual y salvífico de Dios (EG 164).

En teología, el amor a la sabiduría de Dios se transforma en la sabiduría del amor de Dios. Dios es Amor y Misericordia. El joven Juan Baustista Montini escribió: «No basta decir: Dios es Amor, Dios ha amado el mundo; es necesario agregar: Dios es Misericordia, Dios ha amado un mundo pecador ${ }^{16}$. Pablo VI invocaba la dolcissima misericordia y recordaba el binomio agustiniano: miseria hominis plena est terra, misericordia Domini plena est terra. Juan Pablo II dedicó su segunda encíclica a Dios Dives in misericordia. Benedicto XVI tituló su encíclica programática Deus caritas

${ }^{16}$ Cf. Luciano Eusebi. "Dio é Misericordia". Istituto Paolo VI. Notiziario 71 (2016): 7-13, 7. 
est. Francisco dice que el nombre de Dios es misericordia, recreando la antigua cuestión de los nombres divinos. Dios es Amor misericordioso, como muestra la doctrina enseñada por santa Teresita del Niño Jesús y santa Teresa de Calcuta.

Dios, «rico en misericordia» (Ex 34,6; Ef 2,4) sorprende con la iniciativa abundante de su amor. Dios es Amor en exceso, excessus amoris. En la Carta Misericordia e misera Francisco afirma que «la misericordia se excede, siempre va más allá» (n. 19). El Amor de Dios se despliega hacia todos los míseros y las víctimas que sufren las tremendas miserias del mal, el pecado, el dolor y la muerte. La reforma de la Iglesia busca comunicar con transparencia ese amor reflejado en el rostro del Cristo pascual y resumido en la sentencia: «sean misericordiosos como el Padre de ustedes es misericordioso» $(\operatorname{Lc} 6,26)^{17}$. G. Lafont observa que la teología desarrollada por Francisco vincula el primado del Amor misericordioso de Dios y la primacía del Pueblo de Dios en la figura de la pirámide invertida: «el orden sinodal es una manera de expresar el primado del Amor - Misericordia (de Dios) en el nivel de la Iglesia» ${ }^{18}$.

La eclesiología del Pueblo de Dios es correlativa a la antropología cristiana. La CTI funda la dignidad de todos los seres humanos en una antropología de la imago Dei, que se ahonda por la filiación divina y la fraternidad cristiana $(1983,2.2 ; 2004,10)$ y se desarrolla hacia su plenitud escatológica, porque «Dios es el Novísimo de la creatura» (1992, 1.2.3). Los estudios son: Dignidad y derechos de la persona humana (1983); Cuestiones actuales de escatología (1992); Comunión y servicio: La persona humana creada a imagen de Dios (2004); En busca de una ética universal (2009); La libertad religiosa para el bien de todos (2019). En 2008 la Comisión Bíblica publicó Biblia y moral. Raíces bíblicas del obrar cristiano.

\subsection{La IgLesia de CRIsto}

El contexto está dado por la renovación de la eclesiología en el siglo pasado, «el siglo de la Iglesia». Diversas líneas confluyeron en el

\footnotetext{
17 Cf. Carlos María Galli. "Revolución de la ternura y reforma de la Iglesia". Medellín 170, n. ${ }^{\circ} 3$ (2018): 73-108.

18 Ghislain Lafont. Petit essai sur le temps du pape Francois. Paris: Cerf, 2017, 138; cf. 190, 194, 202, 252, 268.
} 
Vaticano II, Concilio de la Iglesia sobre la Iglesia. El Concilio contempla a la Iglesia - mysterium lunae - desde de Cristo: Lumen gentium cum sit Christus (LG 1). Esta comunión formada por hombres -Ecclesia ex hominibus - participa del misterio de la Santísima Trinidad -Ecclesia de Trinitate- que, por la Encarnación del Hijo y el Don del Espíritu, se comunica al ser humano y reúne al Pueblo de Dios de entre las naciones: De Trinitate plebs adunata (LG 4). La Iglesia es misterio/sacramento de comunión del Pueblo de Dios peregrino y misionero al servicio del Reino de Dios.

El Vaticano II promovió la renovación del tratado De Ecclesia en la teología fundamental y dogmática, y consecuentemente, las bases de las disciplinas de la historia de la Iglesia, el ecumenismo, la teología pastoral, el derecho canónico, la liturgia. En la primera plenaria de 1969 Yves Congar propuso que «la Comisión debía aplicar y continuar elaborando la eclesiología del Concilio Vaticano II $»^{19}$. Entre los temas de ese quinquenio se estudiaron cuestiones eclesiológicas. Algunas fueron publicadas (documentos 2, 3, 6, 7) y otras, como la de la colegialidad, sirvieron directamente al Sínodo de los Obispos. Entonces el estudio del Vaticano II no entró de lleno, a pesar de que la CTI tenía grandes eclesiólogos conciliares: Philips, C. Colombo, Congar, De Lubac, Rahner, Ratzinger, Vagaggini...

Los documentos eclesiológicos son: La apostolicidad de la Iglesia y la sucesión apostólica (1973); Temas selectos de eclesiología (1985); La fe y la inculturación (1988); El Cristianismo y las religiones (1997); Memoria y reconciliación: La Iglesia y las culpas del pasado (2000); El sensus fidei en la vida de la Iglesia (2014); La sinodalidad en la vida y en la misión de la Iglesia (2018). A éstos les sumo los estudios sobre los misterios sacramentales: El sacerdocio católico (1970); El sacramento del matrimonio (1977); El diaconado (2002); El bautismo (2007); La reciprocidad entre fe y sacramentos en la economía sacramental (2020), que en ese marco analiza los sacramentos de la iniciación cristiana y el matrimonio.

En el tercer quinquenio la CTI, movida por su nuevo presidente, el cardenal Joseph Ratzinger, estudioso de la eclesiología, analizó algunos de sus temas por varias circunstancias. Una de las más importantes fue la convocatoria de Juan Pablo II a celebrar en 1985 una asamblea extraordinaria del Sínodo de los Obispos para celebrar, verificar y promover la realización del Vaticano II a sus 20 años. Ese sínodo impulsó a la CTI a

\footnotetext{
19 Avallone. La Commissione Teologica Internazionale, 87.
} 
estudiar la eclesiología conciliar. Así nació el documento Temas selectos de eclesiología. Luego, en 1988, la PCB publicó su valioso documento Unidad y diversidad en la Iglesia.

Temas selectos de eclesiología desarrolla diez cuestiones nuevas o debatidas: La fundación de la Iglesia por Jesucristo; La Iglesia nuevo Pueblo de Dios; La Iglesia como misterio y sujeto histórico; Pueblo de Dios e inculturación; Iglesias particulares e Iglesia universal; El nuevo Pueblo de Dios como sociedad ordenada jerárquicamente; El sacerdocio común en su relación al sacerdocio ministerial; La Iglesia como sacramento de Cristo; La única Iglesia de Cristo; El carácter escatológico de la Iglesia: Reino e Iglesia.

Los capítulos dos y tres responden al debate en torno a la noción Pueblo de Dios y la elaboran de forma original. Reconoce: "podemos afirmar que se ha preferido (en las últimas décadas) Pueblo de Dios a las otras expresiones a las que el Concilio recurre para expresar el mismísimo misterio, como Cuerpo de Cristo y Templo del Espíritu. La elección ha estado motivada en razones tanto teológicas como pastorales» $(1985,2,1)$. Y explica: «el Pueblo de Dios es simultáneamente misterio y sujeto histórico, de modo que el misterio constituye al sujeto histórico y el sujeto histórico revela al misterio» $(1985,3,1)^{20}$.

Agrego un comentario que excede ese texto. La teología comprende la Iglesia como misterio o sacramento de comunión que vive como Pueblo de Dios peregrino y misionero. La comunión trinitaria, cristológica, pneumatológica y eucarística del Cuerpo de Cristo es fuente de la figura social e histórica del Pueblo de Dios. «Comunión» se emplea en sentido predicativo: la Iglesia es comunión; "Pueblo de Dios» es una noción subjetiva porque señala al sujeto común del misterio, el nosotros de la Iglesia en la historia.

Mi Facultad de Teología fue la primera institución académica que hizo un comentario completo a la Lumen gentium en 1965 y explicó, en textos de Ricardo Ferrara y Lucio Gera ${ }^{21}$, su lógica arquitéctónica en base a las

${ }^{20}$ Cf. Giuseppe Colombo. "Il Popolo di Dio e il misterio della Chiesa nell'ecclesiologia postconciliare”. Teologia 10 (1985): 97-169.

21 Estos dos grandes teólogos argentinos fueron los únicos miembros de la CTI hasta 2014: Lucio Gera (1924-2012) en el primer quinquenio 1969-1974; Ricardo Ferrara (1930-) en el quinquenio 2004-2009. 
categorías Misterio y Pueblo, que presiden sus dos primeros capítulos ${ }^{22}$. Con el papa Francisco la teología del Pueblo de Dios recupera el lugar central que tuvo en el Vaticano II y fue desdibujado durante tres décadas. Este acento se vincula a la recepción hecha en la comunidad teológica argentina, en especial a una reflexión centrada en el santo pueblo fiel como sujeto de un modo de vivir la fe y crear cultura en una trama histórica concreta ${ }^{23}$. En ese marco observo que el nombre «teología del pueblo» es sugestivo, pero, a mi juicio, puede resultar simplificador si la voz pueblo sólo es comprendida como una comunidad secular de carácter cultural o político. Nuestra reflexión teológica piensa dos sentidos análogos del concepto pueblo, uno eclesial y otro civil. Por eso prefiero hablar de la teología argentina del Pueblo de Dios, del pueblo y los pueblos, y de la pastoral popular, porque ella desarrolla una eclesiología, una teología de la historia y la cultura, y una teología pastoral que considera la misión evangelizadora de la Iglesia entre los pueblos y une la piedad popular con la opción por los pobres ${ }^{24}$.

La CTI considera la sinodalidad como modus vivendi et operandi del Pueblo de Dios en la historia. Piensa no sólo la sinodalidad en la Iglesia sino la sinodalidad de la Iglesia. Hace una analogía de la vida sinodal, una realidad que se da y se dice de varios modos. Sistematiza tres sentidos interrelacionados: el estilo peculiar que califica el modo ordinario de ser y obrar de la Iglesia; las estructuras y los procesos que expresan la comunión a nivel institucional; los acontecimientos — de un sínodo diocesano a un

${ }^{22}$ Cf. Ricardo Ferrara et al. "Lumen gentium. Comentario a la Constitución conciliar sobre la Iglesia”. Teología 7 (1965) 123-230 y 8 (1966) 3-105; los dos textos referidos fueron reeditados en Virginia R. Azcuy, José Carlos Caamaño, y Carlos María Galli., eds. La Eclesiología del Concilio Vaticano II. Buenos Aires: Agape, 2015, 61-171.

${ }^{23}$ Cf. Juan Carlos Scannone. La teología del pueblo. Raíces teológicas del Papa Francisco. Santander: Sal Terrae, 2017, 15-93, 181-274. Francisco. "El Padre Miguel Ángel Fiorito S.I.: Maestro del diálogo”. La Civiltà Cattolica. Iberoamericana 36 (2020): 9-23. José Luis Narvaja. "Miguel Ángel Fiorito. Una riflessione sulla religiosità popolare nell'ambiente di Jorge Mario Bergoglio”. La Civiltà Cattolica 4027 (2018): 18-29. Masssimo Borghesi. Jorge Mario Bergoglio. Una biografia intellettuale. Milano: Jaca Book, 2017, 67-77.

${ }^{24}$ Cf. Carlos María Galli. "Die Ekklesiologie von Papst Franziskus: Missionarische Konversion des Volkes Gottes”. En Barmherzigkeit und zärtliche Liebe. Das theologische Programm von Papst Franziskus, editado por Kurt Appel y Jakob Helmut Deibl, 39-56. Freiburg im Breisgau: Herder, 2016. Id. "Il Popolo di Dio, il popolo e i popoli. Papa Francesco e la teologia argentina”. En Da Puebla ad Aparecida. Chiesa e società in America Latina 1979-2007, a cura di Gianni La Bella y Massimo De Giuseppe, 277-296. Roma: Carocci, 2019. 
concilio ecuménico - donde la Iglesia actúa sinodalmente a nivel local, regional y universal $(2018,70)^{25}$.

Destaco dos líneas transversales que atraviesan la reflexión eclesiológica-pastoral de la CTI.

1. La Comisión hace un discernimiento de las religiones y de la modernidad. En línea con Dignitatis humanae y Nostra aetate analiza la dimensión religiosa y los valores de grandes religiones no cristianas. El cristianismo y las religiones presenta los fundamentos teológicos del diálogo interreligioso y del valor salvífico de las religiones, expresiones sociales e históricas de la vida religiosa. Otros documentos disciernen aspectos de religiones concretas, como aquellos relativos a la inculturación (1988), la escatología (1990), la redención (1995), el monoteísmo trinitario (2014), la libertad religiosa (2019).

En línea con la Gaudium et spes la CTI hace un discernimiento fragmentario pero valioso de algunas tendencias ético-culturales de la cultura moderna en los documentos sobre los derechos de la persona $(1983,2004)$, la inculturación (1988), la hermenéutica dogmática (1989), la salvación y la liberación (1976, 1995, 2007), la libertad religiosa (2019), la ley natural y la ética universal (2009).

2. La CTI pensó la inculturación de la teología (1976, IV; 1988, III,1; $2014,4,2)$. Inculturar la teología implica que las iglesias locales en cada gran territorio cultural indaguen "por qué caminos puede llegar la fe a la inteligencia teniendo en cuenta la filosofía o la sabiduría de los pueblos» (AG 22b). Esa frase es, para mí, la carta magna de la inculturación teológica, y «la última palabra del Concilio sobre el problema hermenéutico» ${ }^{26}$. Desde entonces surgieron varias teologías desde contextos particulares.

En 1976, el texto Promoción humana y salvación cristiana unió el interés del primer quinquenio por una teología de la esperanza con la preocupación del segundo por la teología de la liberación. Ese documento tuvo juicios más equilibrados que las observaciones realizadas en el texto posterior de escatología (1990, 2), el cual no recogió el aporte de la segunda instrucción Libertatis conscientiae de la CDF en 1986. De paso señalo que ya en 1975 la ponencia de Karl Lehmann en la CTI percibió el

${ }^{25}$ Cf. Carlos María Galli. "Du nouveau dans la théologie catholique sur la synodalité”. Proche Orient Chrétien 69 (2019): 13-29.

${ }^{26}$ Cf. Christoph Theobald. La réception du concile Vatican II. 1. Accéder à la source. Paris: Cerf, 2009, 313-314. 
peculiar acento argentino en la teología latinoamericana, luego analizado por Walter Kasper a propósito de Francisco ${ }^{27}$.

El saber teológico arraiga en la sabiduría teologal del Pueblo de Dios vivida en distintas culturas y expresada en la piedad católica popular. En 1996, en una reunión convocada por el Consejo Episcopal Latinoamericano y la Congregación para la Doctrina de la fe, presidida por el cardenal J. Ratzinger, los dieciseis participantes suscribimos esta proposición: «se debe proseguir en el camino de la inculturación de la reflexión teológica para que ella sea plenamente católica y plenamente latinoamericana ${ }^{28}$.

\section{LA FIGURA SINODAL DEL «TEÓLOGO» EN UNA TEOLOGÍA TRIDIMENSIONAL}

En 2019, en el Cincuentenario de la CTI, Francisco expresó: «Después de cincuenta años de intenso trabajo aún queda un largo camino por recorrer, pero recorriéndolo la Comisión Teológica cumplirá su vocación de ser también un modelo y un estímulo para aquéllos -laicos y clérigos, hombres y mujeres- que quieran dedicarse a la teología». Esta forma sinodal de hacer teología puede ser modelo y estímulo para los que hacen teología.

Por eso termino haciendo seis reflexiones para las nuevas generaciones teológicas.

1. La CTI muestra la singularidad del teólogo católico que profesa la fe que busca y sabe entender (fides quaerens et sapiens intelligere) y cultiva una inteligencia que busca y sabe creer (intellectus quaerens et sapiens credere). La condición confesante y la cualidad científica le dan una «función de mediación» $(1975,12)$ entre el sensus fidelium del Pueblo de Dios y el servicio doctrinal del magisterio. En 2015, en el centenario de mi facultad de Buenos Aires, Francisco pidió a quienes hacen teología

27 Karl Lehmann. "Problemas metodológicos y hermenéuticos de la teología de la liberación”. En Teología de la liberación, Comisión Teológica Internacional, 3-42, nota 92. Madrid, BAC, 1978. Walter Kasper. Papa Francesco. La rivoluzione della tenerezza e dell'amore. Brescia: Queriniana, 2015, 57-77.

${ }_{28}$ Consejo Episcopal Latinoamericano. El futuro de la reflexión teológica en América Latina. Bogotá: CELAM, 1996, 367. 
ser hijos de su pueblo, profundos creyentes, profetas en las fronteras, $\mathrm{y}$ pensar rezando y rezar pensando ${ }^{29}$.

La CTI invita a hacer teología sinodalmente por un trabajo responsable personal y comunitario-colegial.

«Junto con la experiencia de fe y la contemplación de la verdad del Pueblo fiel y con la predicación de los Pastores, la teología contribuye a la penetración cada vez más profunda del Evangelio. Además, como en el caso de todas las vocaciones cristianas, el ministerio de los teólogos, al tiempo que personal, es también comunitario y colegial. La sinodalidad eclesial compromete también a los teólogos a hacer teología en forma sinodal, promoviendo entre ellos la capacidad de escuchar, dialogar, discernir e integrar la multiplicidad y la variedad de las instancias y de los aportes» (2018, 75, cf. 110-114).

2. Johann Adam Möhler, el padre de la eclesiología moderna, al plantear la necesidad de armonizar las oposiciones polares (Gegensätze) que enriquecen la pluralidad en la unidad, ponía la imagen del coro con la variedad de sus voces y el arte del director que logra la armonía. "Sin la variedad y la diferencia, resulta una monotonía que fatiga; sin la armonía, una disonancia que choca» ${ }^{30}$. Para Karl Rahner «tocamos constantemente la sinfonía inacabada de la gloria de Dios y nunca pasamos del ensayo general» ${ }^{31}$. La verdad es sinfónica con consonancias y disonancias. Dios ejecuta una sinfonía bella en la composición que crea y también en la orquesta que la interpreta. La música logra resolver tensiones mostrando la pluralidad inagotable que la precede y que reintegra en una unidad superior, en la que cada nota e instrumento es un humilde fragmento. Ésta es la grandeza de la humildad del trabajo teológico coral.

${ }^{29}$ Cf. Francisco. "Discernir y reflexionar en el aquí y ahora. Mensaje del Papa por el Centenario de la Facultad de Teología de la Pontificia Universidad Católica Argentina". L'Osservatore romano (edición semanal en lengua española) 4/9/2015, 12 13.

30 Johann Adam Möhler. Die Einheit in der Kirche oder das Prinzip des Katholizismus dargestellt im Geist der Kirchenväter der drei ersten Jahrhunderte (1825). Editado por Josef Rupert Geiselmann. Darmstadt, 1957, § 46; cf. §§ 31, 35, 65.

${ }^{31}$ Karl Rahner. Das Konzil - Ein neuer Beginn. Freiburg im Breisgau: Herder, 1965, 13; cf. 20-23. 
3. La teología puede ser pensada de forma tridimensional como scientia fidei, prophetia spei, sapientia amoris ${ }^{32}$. Por la circularidad de la vida teologal, la teología piensa una fe sostenida por la esperanza y vivificada por el amor. Una teología teologal, centrada en Dios, es ciencia de la fe, profecía de la esperanza, sabiduría del amor. M.-D. Chenu mostró, con el conocimiento limitado que tenía entonces de Francisco de Vitoria y Bartolomé de las Casas, que ambos ayudaron a la causa indiana porque sabios y profetas se complementan en la Iglesia ${ }^{33}$. El coro teológico necesita sabios profetas y profetas sabios que se complementen mutuamente en el servicio a la Palabra y al Pueblo de Dios.

4. La vocación teológica - en sus variadas voces y en su armonía coral- escucha, piensa, dice y alaba al Deus semper maior. Hay, al menos, tres formas del lenguaje discursivo teológico que tienen como referente al singular Dios según se lo conjugue en primera, segunda o tercera persona singular. En primera persona, la fe responde al mensaje propuesto por Dios o en nombre de Dios, dicho por el oráculo del revelador, el anuncio del profeta o la palabra de Jesús, que es la Palabra de Dios: Yo les digo. En ese lenguaje Dios se comunica y nos habla como amigo. En segunda persona, las plegarias elevadas a Dios piden, agradecen y cantan al Padre por su Don y sus dones. Conversamos con Él como un Tú, como Jesús hablaba a solas con su Padre: Te alabo, Padre. En tercera persona, hablando acerca de Dios como de un Él o un Tercero único, el teólogo profiere un discurso acerca de Dios y de su amor salvador, como Jesús hablaba de su Padre: el Padre es misericordioso.

5. La teología nace en el silencio y la escucha de la Palabra de Dios y culmina en el canto y la contemplación de la Trinidad. El diá-logo con Dios es una forma de participar en la Teo-logía de Dios que es Logos y Dia-logos $^{34}$. Deseamos escuchar a Dios, conversar con Dios y hablar de Dios en nuestro tiempo.

El discurso coral y sinfónico sobre Dios y su providencia salvífica, dicho en tercera persona, se funda en la Palabra que Él nos dirige personalmente en la carne de Jesús. San Anselmo unió argumentos y plegarias

\footnotetext{
${ }^{32}$ Cf. Carlos María Galli. De amar la sabiduría a creer y esperar en la Sabiduría del Amor. Buenos Aires: Guadalupe, 2012, 11-64.

33 Cf. Marie-Dominique Chenu. "Profetas y teólogos en la Iglesia". En El Evangelio en el tiempo. Barcelona: Estela, 1966, 191-201.

${ }^{34}$ Cf. Joseph Ratzinger. Introducción al cristianismo. Salamanca: Sígueme, 1969, 151-152.
} 
en una dialéctica orante ${ }^{35}$. Ejerció una ratio orante y argumentativa que reza pensando y piensa rezando. Contribuyó a aunar el credo ut experiar y el credo ut intellegam. El primer capítulo del Proslogion culmina en una plegaria que sintetiza la sabiduría monástica y el espíritu escolástico.

«Te confieso, Señor, y te doy gracias porque creaste en mí tu imagen, para que me acuerde de Ti, te piense, te ame... No intento Señor, llegar a tu altura porque de ningún modo puede comparar con ella mi inteligencia, pero deseo entender de alguna manera tu verdad, que cree y ama mi corazón. No busco entender para creer, sino que creo para entender (credo ut intellegam). También creo esto: que si no creyera, no entendería».

6. La unión entre la razón teológica (scientia), la sabiduría espiritual (sapientia) y la profecía evangelizadora (prophetia) nos mueve a renovar la pastoralidad de toda la teología en una Iglesia sinodal en salida misionera.

«Este es un momento oportuno para impulsar con ponderada y profética determinación, a todos los niveles, un relanzamiento de los estudios eclesiásticos en el contexto de la nueva etapa de la misión de la Iglesia, caracterizada por el testimonio de la alegría que brota del encuentro con Jesús y del anuncio de su Evangelio, como propuse programáticamente a todo el Pueblo de Dios en la exhortación Evangelii gaudium.

[...] llegó el momento en el cual los estudios eclesiásticos reciban la sabia renovación que se requiere para colaborar en la transformación misionera de una Iglesia "en salida" »"

\section{REFERENCIAS}

Avallone, Enmanuele. La Comissione Teologica Internationale. Storia e prospettive. Venezia: Marcianum Press, 2016.

Benedicto XVI. "Catequesis sobre Juan Duns Scoto en la audiencia general del 7/7/2010”. En Los Maestros III. Franciscanos y dominicos. Catequesis de los miércoles. Buenos Aires. Agape, 2010.

${ }^{35}$ Cf. Michel Corbin. Prière et raison de foi. Introduction à l'oeuvre de saint Anselme. Paris: Cerf, 1992, 175.

${ }^{36}$ Francisco. Constitución Apostólica 'Veritatis gaudium' sobre las universidades y facultades eclesiásticas. Città del Vaticano: LEV, 2018, Proemio 1 y 3. 
190 CARLOS MARÍA GALLI, EL CINCUENTENARIO DE LA COMISIÓN TEOLÓGICA...

Borghesi, Masssimo. Jorge Mario Bergoglio. Una biografia intellettuale. Milano: Jaca Book, 2017.

Brito, Emilio. "Gloria Unigeniti. Pour une christologie post-hégélienne”. En La christologie de Hegel. Verbum crucis, 535-656. Paris: Beauchesne, 1983.

Chenu, Marie-Dominique. "Profetas y teólogos en la Iglesia”. En El Evangelio en el tiempo, 191-201. Barcelona: Estela, 1966.

Colombo, Giuseppe. "Il Popolo di Dio e il misterio della Chiesa nell'ecclesiologia postconciliare”. Teologia 10 (1985): 97-169.

Comisión Teológica Internacional. Documentos 1969-2014. Madrid: BAC, 2017.

Commission Théologique Internationale. Textes et Documents I (19691985). Paris: Cerf, 1988.

Commission Théologique Internationale. Documents II (1986-2009). Paris: Cerf, 2013.

Commissione Teologica Internazionale. Documenti 1969-2004. Bologna: EDS, 2006 (2010).

Congar, Yves. "Pour une christologie pneumatologique". En Je crois en l'Esprit Saint III, 219-228. Paris: Cerf, 1983.

Congregación para la Doctrina de la Fe. Documentos 1966-2007. Madrid: BAC, 2007.

Congregación para la Doctrina de la Fe. Documentos 2008-2011. Madrid: BAC, 2012.

Consejo Episcopal Latinoamericano. El futuro de la reflexión teológica en América Latina. Bogotá: CELAM, 1996.

Corbin, Michel. Prière et raison de foi. Introduction à l'oeuvre de saint Anselme. Paris: Cerf, 1992.

Descamps, Albert. "In memoriam Monseigneur G. Philips”. Revue Theólogique de Louvain 3 (1972): 378-381.

Eusebi, Luciano. “Dio é Misericordia”. Istituto Paolo VI. Notiziario 71 (2016): 7-13.

Ferrara, Ricardo y et al. "Lumen gentium. Comentario a la Constitución conciliar sobre la Iglesia”. Teología 7 (1965): 123-230.

Francisco. "Discernir y reflexionar en el aquí y ahora. Mensaje del Papa por el Centenario de la Facultad de Teología de la Pontificia Universidad Católica Argentina”. L'Osservatore romano (edición semanal en lengua española) 4/9/2015, 12-13. 
Francisco. Constitución Apostólica 'Veritatis gaudium' sobre las universidades y facultades eclesiásticas. Città del Vaticano: LEV, 2018, Proemio 1 y 3.

Francisco. "El Padre Miguel Ángel Fiorito S.I.: Maestro del diálogo". La Civiltà Cattolica. Iberoamericana 36 (2020): 9-23.

Galli, Carlos María. De amar la sabiduría a creer y esperar en la Sabiduría del Amor. Buenos Aires: Guadalupe, 2012.

Galli, Carlos María. "Die Ekklesiologie von Papst Franziskus: Missionarische Konversion des Volkes Gottes". En Barmherzigkeit und zärtliche Liebe. Das theologische Programm von Papst Franziskus, editado por Kurt Appel y Jakob Helmut Deibl, 39-56. Freiburg im Breisgau: Herder, 2016.

Galli, Carlos María. "Revolución de la ternura y reforma de la Iglesia". Medellín 170, n. 3 (2018): 73-108.

Galli, Carlos María. "Pensar conjuntamente en teología y en filosofía. Un estilo dialogal, itinerante, integrador". Teología 129 (2019): 9-65.

Galli, Carlos María. "Il Popolo di Dio, il popolo e i popoli. Papa Francesco e la teologia argentina". En Da Puebla ad Aparecida. Chiesa e società in America Latina 1979-2007, a cura di Gianni La Bella, y Massimo De Giuseppe, 277-296. Roma: Carocci, 2019.

Galli, Carlos María. "Du nouveau dans la théologie catholique sur la synodalité". Proche Orient Chrétien 69 (2019): 13-29.

González de Cardedal, Olegario. Cuatro poetas desde la otra ladera. Unamuno, Jean Paul, Machado, Oscar Wilde. Prolegómenos para una cristología. Madrid: Trotta, 1996.

Kasper, Walter. Teología e Iglesia. Barcelona: Herder, 1989.

Kasper, Walter. Papa Francesco. La rivoluzione della tenerezza e dell'amore. Brescia: Queriniana, 2015.

Ladaria, Luis. "Cristología del Logos y cristología del Espíritu". Gregorianum 61 (1980): 353-360.

Ladaria, Luis. "El hombre a la luz de Cristo en el Concilio Vaticano II". En Vaticano II. Balance y perspectivas, editado por René Latourelle, 705-714. Salamanca: Sígueme, 1989.

Lafont, Ghislain. Histoire théologique de l'Église catholique. Itinéraire et formes de la théologie. Paris: Cerf, 1994.

Lafont, Ghislain. Petit essai sur le temps du pape Francois. Paris: Cerf, 2017. 
Lehmann, Karl. "Problemas metodológicos y hermenéuticos de la teología de la liberación". En Teología de la liberación, Comisión Teológica Internacional, 3-42, nota 92. Madrid, BAC, 1978.

Möhler, Johann Adam. Die Einheit in der Kirche oder das Prinzip des Katholizismus dargestellt im Geist der Kirchenväter der drei ersten Jahrhunderte (1825). Editado por Josef Rupert Geiselmann. Darmstadt, 1957.

Narvaja, José Luis. "Miguel Ángel Fiorito. Una riflessione sulla religiosità popolare nell'ambiente di Jorge Mario Bergoglio". La Civiltà Cattolica 4027 (2018): 18-29.

Philips, Gérard. "Méthodes théologiques de Vatican II". En Théologie. Le service théologique dans l'Église. Mélanges offers au Pére Congar, 11-35. Paris: Cerf, 1974.

Rahner, Karl. Das Konzil - Ein neuer Beginn. Freiburg im Breisgau: Herder, 1965.

Ratzinger, Joseph. Introducción al cristianismo. Salamanca: Sígueme, 1969.

Scannone, Juan Carlos. La teología del pueblo. Raíces teológicas del Papa Francisco. Santander: Sal Terrae, 2017.

Sesboüé, Bernard. Jesucristo, el único Mediador. Salamanca: Secretariado Trinitario, 1990.

Theobald, Christoph. La réception du concile Vatican II. 1. Accéder à la source. Paris: Cerf, 2009.

Tilliette, Xavier. Le Christ de la Philosophie. Paris: Cerf, 1990.

Tilliette, Xavier. La Settimana Santa dei filosofi. Brescia: Morcelliana, 1992. 